\title{
Sobre uma possível morada do real na ficção
}

On a possible inhabitance of the real in fiction

\section{Pedro Rodrigo Peñuela Sanches}

Pedro Rodrigo Peñuela Sanches Doutorando no Programa de Pós-Graduação em Artes Cênicas da Escola de Comunicações e Artes da Universidade de São Paulo.

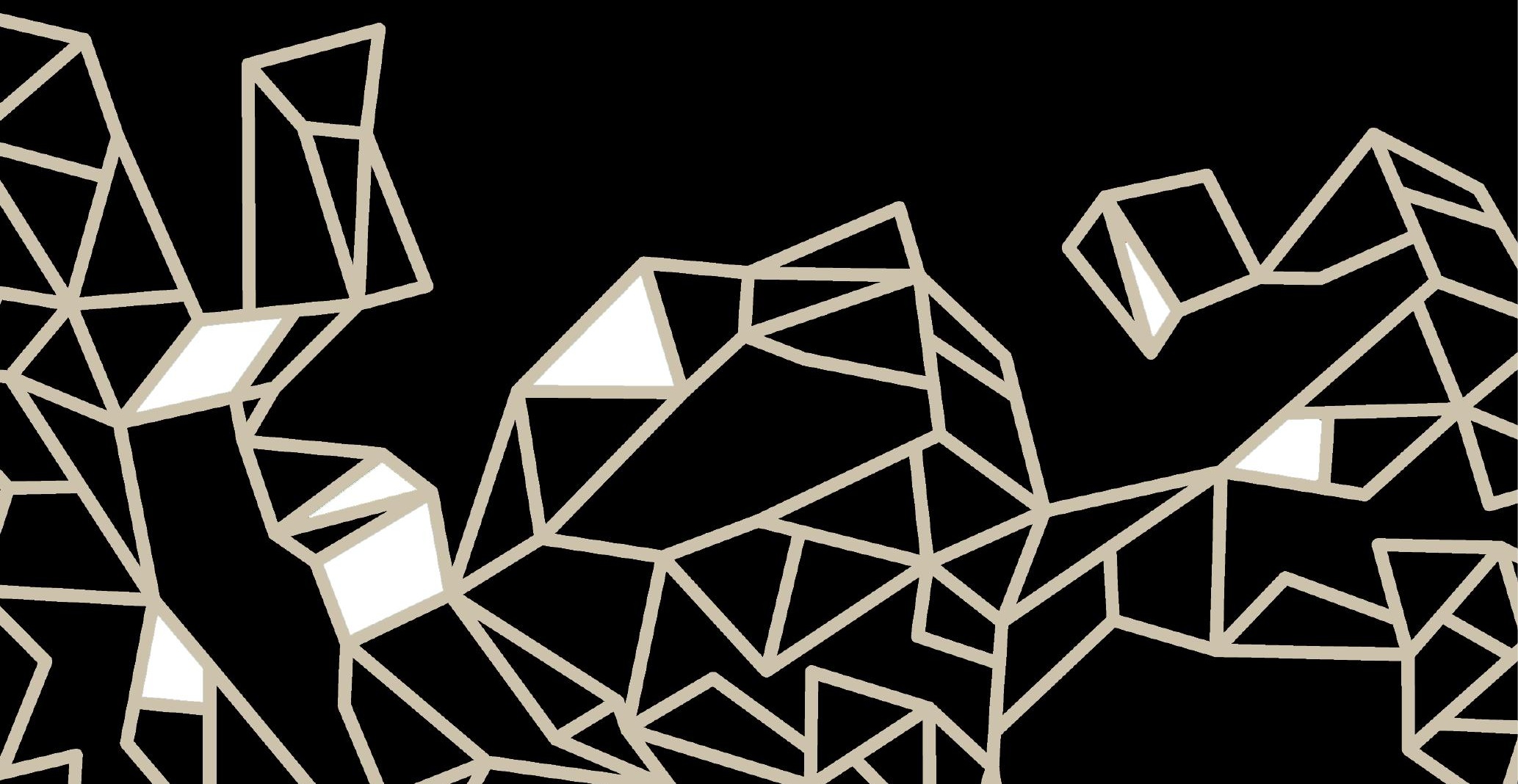




\section{Resumo}

Este trabalho procura revisar ideias de alguns teóricos do teatro e da dança com relação às produções cênicas realizadas a partir da década de 1960 (que têm sido nomeadas como "pós-modernas", "pós-dramáticas", "teatro performativo", entre outras expressões que procuram salientar sua diferenciação com relação às artes cênicas de certa época ou conceituação anteriores), a fim de apontar limites da crítica à representação que tais teorizações pretendem realizar. Discute-se em que medida certo caminho de desconstrução da lógica da representação tende a efetuar-se sobre os mesmos fundamentos conceituais de tal lógica, e sobre um mesmo tipo de pensamento dicotômico que a estrutura. Em seguida, tomando como base ideias do filósofo Jacques Rancière, pretende-se apontar outras possibilidades de crítica da representação por meio de sua reconceituação da noção de ficção.

Palavras-chave: Real, Ficção, Teorias das Artes Cênicas, Representação.

\section{Abstract}

This article reviews theories about Theater and Dance regarding performing art productions presented since the 1960s (which have been called "post-modern", "post-dramatic", "performative theater", among other notions which aim to mark a kind of turning point in performing arts), in order to point out limits of the critique to representation that such theories intend to accomplish. It is discussed at what level a certain deconstructive way of the logics of representation tend to be built on the same foundations, structured in certain dichotomies, of such logic. Moreover, considering Jacques Rancière's thought, other possibilities for a critique of representation are proposed, based on a specific reconceptualization of "fiction".

Keywords: Real, Fiction, Performing Arts Theories, Representation.

Um "desejo de alcançar o objeto verdadeiro, [isto é] o objeto real", como coloca José Gil (2009, p. 151), atravessa as criações de diferentes artistas da cena a partir dos anos 1960, aparecendo, por exemplo, nas recusas de Yvonne Rainer (uma das principais artistas da chamada dança "pósmoderna") que constituem um de seus mais contundentes manifestos: "não 
ao espetáculo, não ao virtuosismo, não às transformações e à magia e ao uso de truques, [...] não à sedução [...], não ao fato de alguém se mover ou se fazer mover" (RAINER apud GIL, 2009, p. 151).

Diferentes criadores das artes cênicas, surgidos na mesma época de Rainer, compartilham, além de um mesmo tempo histórico, intenções claramente formuladas de desconstrução de certos dispositivos constituintes de uma tradição cênica hegemônica até então no Ocidente. ${ }^{1}$

O trabalho de tais artistas mobilizou a teorização sobre teatro e dança no sentido da produção de novos conceitos, ou, antes ainda, de uma nomenclatura que pudesse mais precisamente circunscrever os fenômenos e questões que apresentam e, ao mesmo tempo, provocar uma reflexão crítica coerente com as investigações e discussões que caracterizam seus trabalhos.

Sally Banes (1987), uma entre os teóricos e historiadores da dança que procuraram discutir essa(s) geração(ões) de criadores (surgidos entre as décadas de 1960 e 1990), agrupa-os sob o termo "dança pós-moderna", buscando principalmente discutir as relações específicas de suas obras com as questões do modernismo nas artes em geral.

O que Banes identifica como ponto de partida e articulador fundamental entre os trabalhos dos "pós-modernos" seria a oposição à lógica da representação em cena, fundada na criação de um espaço ficcional-metafórico baseado na reprodução de uma realidade à qual se faz referência por meio de artifícios cênicos, tais como cenografia, figurino, tempo cênico, dramatização etc. A esse respeito a autora faz referência ao ensaio "Against Interpretation”, de Susan Sontag (1965), que defendia uma recepção e crítica dos trabalhos de arte não baseada na interpretação (entendida como a ação de "adicionar significados"

1 Cabe notar que o discurso que se construiu ao redor desses criadores, ainda que eles próprios reconheçam filiações de seu trabalho ao trabalho de criadores de gerações anteriores, se baseia em considerações de "originalidade" ou ruptura, baseadas na oposição e negação de certos dispositivos hegemônicos instituídos, de modo que o que identificaria esses artistas (inclusive nas classificações críticas construídas por ou sobre eles) começa por aquilo que eles não são ou aquilo que negam como proposta estética (não são dançarinos modernos, não são encenadores dramáticos, recusam o ilusionismo clássico ou moderno etc.). Mais a respeito dessa discussão, cf. Krauss (1986).

2 Termo que começou a ser utilizado pela própria Yvonne Rainer, nos anos 1960, e que a autora mantém em seu trabalho, mas procura matizar criticamente, ao discutir em que medida o "pós-moderno", em dança, refere-se em grande parte a discussões, procedimentos e métodos próprios do modernismo (BANES, 1987, p. XIV-XV). 
aos trabalhos), mas na "valorização da experiência concreta" (BANES, 1987, p. $\mathrm{XVI}$ ). Nesse sentido, para Banes, na medida em que rompem com o esforço por veicular corporalmente narrativas e questões sociológicas ou psicológicas, que teria caracterizado a dança moderna, os criadores da "dança pós-moderna" tornam "o corpo em si mesmo o assunto da dança, mais do que um instrumento a serviço da veiculação de metáforas expressivas" (Ibid., p. XVII).

De maneira análoga a esse caminho de discussão em relação à dança, no campo da teoria teatral, Hans-Thies Lehmann, ao final dos anos 1990, defenderá o termo "teatro pós-dramático", por meio do qual identifica uma espécie de paradigma articulador dos trabalhos de diferentes criadores, caracterizado pela presença de traços similares em suas obras, identificados por Lehmann como:

Ambiguidade, celebração da arte como ficção, celebração do teatro como processo, descontinuidade, heterogeneidade, não textualidade, pluralismo, diversidade de códigos, subversão, multilocalização, perversão, o ator como tema e figura principal, deformação, o texto como um valor autoritário e arcaico, a performance como terceiro elemento entre o drama e o teatro, o caráter antimimético, a rejeição da interpretação. (LEHMANN, 2007, p. 30-31)

Contrariamente, o teatro clássico grego e, igualmente, o teatro renascentista e moderno, incluindo o teatro da primeira metade do século $\mathrm{XX}$, estariam marcados, em geral, pela centralidade do drama. Nas palavras de Lehmann:

O teatro dramático está subordinado ao primado do texto [...]. O texto, por sua vez, permanecia centrado em sua função como texto para interpretação de papeis [...]. Por mais que permaneça questionável em que medida e de que modo o público dos séculos anteriores se entregava às "ilusões" que os truques de palco, os jogos e luzes artificiais, os acompanhamentos musicais, o figurino e a cenografia ofereciam, o teatro dramático era construção de ilusão. Ele pretendia erguer um cosmos fictício e fazer com que "o palco que significa o mundo" aparecesse como um palco que representa o mundo. [...] Totalidade, ilusão e representação do mundo estão na base do modelo "drama". (Ibid., p. 25-26, grifo no original)

Para Lehmann, a centralidade do drama implica uma modalidade de relação entre o teatro e a realidade que abstrai a concretude e a sensorialidade, 
privilegiando considerações interpretativas sobre o "conteúdo" dos acontecimentos e objetos reais. Em suas palavras:

[[No teatro dramático,] fixada no esquema de pensamento "ação/imitação," a visão se desloca da textura do drama escrito, assim como daquilo que se mostra aos sentidos como ação cênica, para se assegurar tão somente do que é representado: do "conteúdo" recebido, da significação, do sentido, enfim. (Ibid., p. 57)

Assim, o teatro pós-dramático romperia com a centralidade da representação (entendida como reprodução de uma realidade externa à qual a mímesis teatral faria referência, como reconstrução ficcional de referentes unívocos correspondentes a cada elemento teatral), visando à realidade instaurada pela própria atuação (não uma realidade fora da cena, evocada mimeticamente), e enfatizando, assim, a corporeidade do ator, a concretude e materialidade dos acontecimentos e objetos cênicos e a desconstrução da linearidade dramática e narrativa, bem como seu apoio em certo uso hierárquico dos recursos cenográficos, de figurino, luz etc.

Josette Féral, outra teórica do Teatro, responde à conceituação de Lehmann, propondo a noção de "teatro performativo" como mais adequada do que a noção de "teatro pós-dramático", atribuindo, portanto, centralidade aos conceitos e reflexões oriundos da arte da performance (e dos performance studies, de autores como Richard Schechner), entendendo, desse modo, que o que fundamentalmente caracteriza o teatro "pós-dramático" seria sua apropriação das estratégias, questões e posicionamentos oriundos da performance.

Analisando diferentes trabalhos que exemplificam o "teatro performativo", ela conclui "o que é comum a todos esses excertos, é um jogo com a representação. Uma forma de representação que nega a si mesma" (FÉRAL, 2008, p. 206, grifo no original), na medida em que desfaz limites entre real e ficcional, privilegia o processo sobre o produto (e, portanto, ação dos criadores "reais" mais do que a ocultação da maquinaria que sustenta a representação ficcional,

3 La chambre d'Isabella, de Juan Lawers (2004); Dortoir, de Gilles Maheu, de meados dos anos 1980; trabalhos de Robert Lepage dos anos 1990; e Eraritjaritjaka-Musée des Phrases, de Heiner Goebbels (2004). 
característica do teatro tradicional), produz acontecimentos cujo sentido não necessita de um referente externo (de uma mímesis), e, notadamente, instaura uma "estética da presença", ao enfatizar "a execução do gesto, a criação da forma, a dissolução dos signos em sua reconstrução permanente" (Ibid., p. 209).

Enfatizando também as relações entre performance e teatro contemporâneo, Erika Fischer-Lichte, outra teórica contemporânea do teatro e performance, parte da descrição da performance Lips of Thomas (1975), de Marina Abramović, para discutir que na arte da performance, a importância da experiência sensorial e da ação suplantam a demanda por compreensão ou intepretação (FISHER-LICHTE, 2008, p. 16), provocando o afeto, antes ou mais intensamente que a reflexão, e superando assim, em certo grau, a separação entre sujeito e objeto, que caracterizaria o paradigma hermenêutico (interpretativo) de produção e recepção de trabalhos de arte:

Para a estética hermenêutica e semiótica, uma distinção clara entre sujeito e objeto é fundamental. O artista, sujeito 1, cria uma artefato distinto, fixo e transferível, que existe independentemente de seu criador. Essa condição permite ao espectador, sujeito 2, fazê-lo objeto de sua percepção e interpretação. [...] Essa possibilidade não foi oferecida na performance de Abramović. A artista não produziu um artefato, mas trabalhou sobre e transformou seu corpo diante dos olhos do público. [...] Nesse processo, a relação entre sujeito e objeto foi estabelecida não como dicotômica mas como oscilatória. As posições de sujeito e objeto não podiam ser mais claramente definidas ou distinguidas uma da outra. (lbid.)

Com essa breve retomada de ideias desses diferentes autores, queremos aqui assinalar que em suas teorizações opera um conjunto em comum de oposições estruturais dicotômicas, tais como: a oposição entre "interpretação" (e, por extensão, "sentido" ou "significação") e "experiência", presente no trabalho de Susan Sontag, retomado por Sally Banes (1987); ou então a oposição tecida por Lehmann (2007) entre signos referidos a uma materialidade externa, ou signos referidos "tão somente a si, à sua presença" (p. 160-161); ou ainda, a oposição entre "entender/interpretar e experienciar", que embasa

4 "Essa realidade [criada pela performance] não era meramente interpretada pela audiência mas primeiro e mais importante, experienciada. Ela provocava um amplo espectro de sensações nos espectadores [...], de longe transcendendo as possibilidades e o esforço 
a tese de Fisher-Lichte (2008), segundo a qual, no encontro com uma performance (como a de Abramović), a ação tem muito mais peso do que seu sentido simbólico, por exemplo, o acontecimento de, em tempo real, a artista estar cortando seu corpo é muito mais importante do que o sentido simbólico que poderia ter o desenho de uma estrela feito pelos cortes, o que corroboraria a ideia de que o acontecimento se opõe à interpretação (Fisher-Lichte, 2008, p. 36). ${ }^{5}$

Essas oposições estariam a serviço de uma crítica à lógica da representação, na medida em que afirmam a emergência de uma arte do real, na qual importa mais os acontecimentos, afetos e materialidades do que (seus opostos) as construções interpretativas de sentido, que, por outro lado, interessariam às ficções de uma arte representacional.

Um autor que constrói uma teorização que caminha em grande medida nessa mesma direção é Hans Ulrich Gumbrecht. Em Produção de presença: o que o sentido não consegue transmitir (2010), Gumbrecht procura construir e apresentar uma trama conceitual que permita produzir conhecimento e abordar a experiência de maneira alternativa à "universalidade da interpretação", ou "paradigma hermenêutico" - que ele entende, (de maneira bastante similar à de Lehmann e Fisher-Lichte), como extração de sentido mediante o trabalho

para refletir, para constituir significado e interpretar eventos. A preocupação central da performance não era entender mas experienciar e lidar com essas experiências." (FISHER-LICHTE, 2008, p. 17).

5 Penso que essa tese se fragiliza enormente ao ignorar em que medida a qualidade do afeto dos espectadores é (ou possa ser) diretamente atravessada pelo fato de que não é com qualquer objeto cortante que Abramović se corta na performance, mas com uma lâmina de barbear, isto é, um objeto cotidiano, usado (em geral por homens), em situações de autocuidado e autocultivo, diretamente ligadas ao "processo civilizador" (conceito de Norbert Elias) e ao cotidiano. A materialidade muito concreta da pele que pode ser rompida por um objeto tão corriqueiro não deixa de evidenciar nossa capacidade de produzir ou de nos inserir em uma cultura que produz e distribui objetos para "facilitar" a sobreviência, mas que podem igualmente destruir. Parece-me claro que o afeto gerado pela ação de cortar e pelo sangue que corre não se dissocia do caráter cotidiano do objeto (e depende disso também), da fragilidade da pele diante desse objeto cortante, do fato de ser uma mulher se cortando, de o corte estar no baixo ventre, de o ambiente ser asséptico e branco (criando um contraste visual com o sangue), entre outras ressonâncias e associações totalmente materiais, mas que costuram a memória de inúmeras experiências, cuja tessitura afetiva é inevitalmente da ordem do sentido, da significação - justamente o que supostamente estaria expulso pela defendida concretude "transcendente" da ação e do afeto. Em outras palavras, não há necessariamente por que opor afeto e sentido/significação, ainda que de fato o sentido não tenha de emergir de alguma tentativa (empobrecedora ou defensiva) de decodificação simbólica direta (do tipo "o corte significa que..."). Para uma discussão crítica mais completa nessa direção, faço referência aos capítulos 3 e 4, de Didi-Huberman (2010). 
do pensamento de um sujeito epistêmico, concebido como externo ao objeto de seu conhecimento, capaz de distanciar-se da materialidade do mundo e sobre ela encontrar ou fabricar sentidos, que ordenariam sua complexidade e opacidade de sentidos iniciais - paradigma que, segundo o autor, se tornou hegemônico na tradição ocidental das humanidades e das artes, em especial a partir dos desdobramentos do pensamento cartesiano nas principais teorizações produzidas neste campo de saber.

Para desmontar esse paradigma, o autor então recorre à filosofia de Heidegger, em especial às noções de: "Ser como acontecimento da verdade", acontecimento não conceitual, pertencente à "dimensão das coisas" (GUMBRECHT, 2010, p. 93); à noção de Dasein, ser-no-mundo, posição ontológica distinta da posição de um sujeito que interpreta ou transforma o mundo; e à distinção entre mundo, lugar das referências culturais, e terra "vinda espontânea para adiante daquilo que continuamente se autoisola e, nessa medida, dá abrigo e esconderijo" (HEIDEGGER apud GUMBRECHT, 2010, p. 99).

A partir desses conceitos, Gumbrecht conceitua a presença a partir da experiência de "efeitos de presença", situados num campo oposto ao dos "efeitos de sentido", concluindo que: "Aquilo de que [...] sentimos falta num mundo tão saturado de sentido, e portanto, aquilo que se transforma num objeto principal de desejo (não totalmente consciente) na nossa cultura [...] são fenômenos e impressões de presença" (GUMBRECHT, 2010, p. 134).

A teorização de Gumbrecht é abrangente e procura articular experiências e debates bastante diversos. No entanto, a nosso ver, carrega um problema

6 Dessa distinção de base entre presença e sentido, Gumbrecht depreenderá a distinção entre dois modelos ou modos ideais de apreensão e constituição da experiência: as culturas da presença e as culturas do sentido. As culturas de sentido (e paradigmaticamente a nossa) seriam caracterizadas por: 1) identificação entre sujeito e pensamento; 2 ) tomar o ser humano como centro separado do mundo; 3 ) considerar o conhecimento como resultado da intepretação; 4) compreender os signos como união de um suporte material a um significado espiritual; 5) valorização da ação do ser humano sobre o mundo; 6) valorização da dimensão temporal por sobre a espacial; 7) transformação da violência concreta sobre os corpos em poder e 8) noção de acontecimento ligada à ideia de inovação e surpresa. Enquanto que, em oposição,, as culturas de presença se caracterizariam por: 1) centro de autorreferência do sujeito situado no corpo; 2) integração entre ser humano e cosmos; 3) conhecimento considerado como resultado de revelação; 4) compreensão do signo como junção de substância e forma (noção aristotélica de signo); 5) busca de harmonização com uma ordem cósmica, e entendimento da ação sobre o mundo como magia; 6) valorização da dimensão espacial por sobre a temporal; 7) acesso direto à possibilidade de violência entre corpos e 8) noção de acontecimento ligada a ciclos de uma cosmologia. 
fundamental: procura superar um paradigma interpretativo/representacional na epistemologia (e na estética) recorrendo, no entanto, a suas categorias estruturantes mais básicas: a própria dicotomia entre sentido e experiência, ou sentido e presença ${ }^{7}$ (dicotomia que também fundamenta as conceituações dos autores e críticos de teatro e dança já citados).

Tal dicotomia, como nos lembra Jacques Rancière (2009, p. 15-18) diretamente correlata à dicotomia entre real e ficção (ou entre verdade e fingimento, interpretação e fato, como várias outras às quais o discurso sobre as artes cênicas "do real" tende a recorrer), que resume e embasa as dicotomias até aqui citadas - já se manifesta na crítica feita ao teatro por Platão, para quem a cena teatral consiste na produção de simulacros, aos quais este opõe o "real" dos corpos em ação na pólis (cada qual tomando seu devido lugar, em uma hierarquia aristocrática que separa o cidadão do homem do trabalho). Aristóteles, em Poética, inverte essa valoração platônica, porém, mantendo ainda a oposição entre real e ficção, mas atribui à ficção um papel mais "positivo", de construir uma ordenação causal dos acontecimentos, que os organizaria de maneira logicamente superior à sua "desordem empírica" (Ibid., p. 54).

De maneira alternativa ao caminho tomado pelos autores citados, consideramos que, acompanhando Rancière, a ruptura com a lógica representacional construída por Platão e Aristóteles com base na separação entre real e ficção, não acontece por meio da valorização de um polo até então desvalorizado (o real) mantendo-se a mesma dicotomia como estruturante da conceituação, mas, mais radicalmente, por uma reconstrução dos sentidos da própria noção de "ficção", portanto, de "real". Essa reconstrução, de acordo com Rancière, emerge antes dos anos 1960, já no século XIX, com a configuração do que ele chama de revolução ou regime estéticos: ${ }^{8}$

7 Dicotomia que justamente percorre tanto a obra de Platão, em sua separação ontológica entre ideias e experiência, como a obra metafísica de Aristóteles, em seu esforço por conceituar como o saber da experiência (um saber incipiente, que decorreria do saber mais primitivo oriundo das sensações) pode vir a ser transformado em conhecimento, pelo trabalho do logos de um sujeito pensante.

8 Manifesto concretamente nas obras de escritores como Flaubert ou Balzac, e formulado claramente nas Cartas sobre a educação estética do homem, de Schiller. Cf. Rancière (2012, p. 56-60). 
A revolução estética redistribui o jogo tornando solidárias duas coisas: a indefinição das fronteiras entre a razão dos fatos e a razão das ficções. [...] A ordenação ficcional deixa de ser o encadeamento causal aristotélico das ações "segundo a necessidade e a verossimilhança". Torna-se ordenação de signos. [...] A "ficcionalidade" própria da era estética se desdobra assim entre dois polos: entre a potência de significação inerente às coisas mudas e a potencialização dos discursos e dos níveis de significação. (RANCIÈRE, 2009, p. 54-55)

Nesse sentido, o regime estético imbrica o real e o ficcional de maneira distinta da ordenação dicotômica aristotélica, pois embaralha a lógica causal linear prevista pela ficção, tal como entendida na ordem da representação: as "coisas mudas", que até então ocupavam um lugar secundário na ordenação ficcional causal, de fato passam a primeiro plano das construções artísticas, não porque contam como coisas em si e por si, como "acontecimento puro" desconectado de qualquer construção ficcional, ou como elementos de algum tipo de "real" silencioso, pré-significante, transcendente às construções discursivas, mas porque a própria ficção deixa de ser ordenação causal de uma inteligibilidade do mundo, e passa a ser constituída e constituinte de "rearranjos materiais dos signos e das imagens, das relações entre o que se vê e o que se diz, entre o que se faz e o que se pode fazer" (Ibid., p. 59, grifo no original).

Portanto, o que está em jogo entre real e ficcional é a distribuição de certa partilha do sensível - do que pode ou não ser sentido, e quando, como e por quem.

Nesse sentido, as colocações de Rancière nos permitem apontar que a aposta na ideia de uma arte que revelaria um real transcendente à ficção e ao discurso tende a reafirmar a lógica da representação (baseada justamente na oposição entre real e ficção), em vez de subvertê-la.

Sendo assim, pensar "modos de ficção" e procurar situar como cada proposição cênica tensiona e transforma certa partilha do sensível, isto é, certas estruturas ficcionais de relação com o mundo sensível, pode implicar uma maneira de transformação mais radical do paradigma da representação, e, portanto, talvez nos permita conceituar o "objeto real", ao qual se refere José Gil, como emergência de embaralhamento nas ordens de ficção e partilha do sensível - transformações nos regimes ficcionais que experienciamos materialmente. 


\section{Referências bibliográficas}

BANES, S. Terpsichore in sneakers: post-modern dance. Middletown: Wesleyan University Press, 1987.

DIDI-HUBERMAN, G. O que vemos, o que nos olha. São Paulo: Editora 34, 2010.

FÉRAL, J. Por uma poética da performatividade: o teatro performativo. Sala Preta, São Paulo, v. 8, n. 8, p. 191-210, 2008.

FISCHER-LICHTE, E. The transformative power of performance. Londres: Routledge, 2008.

GIL, J. Movimento total: o corpo e a dança. São Paulo: lluminuras, 2009.

GUMBRECHT, H. U. Produção de presença: o que o sentido não consegue transmitir. Rio de Janeiro: Contraponto, 2010.

KRAUSS, R. The originality of the avant-garde and other modernist myths. Cambridge: MIT Press, 1986.

LEHMANN, H.-T. Teatro pós-dramático. São Paulo: Cosac Naify, 2007.

RANCIÈRE, J. A partilha do sensível: estética e política. São Paulo: Editora 34, 2009.

O espectador emancipado. São Paulo: Martins Fontes, 2012.

Recebido em 29/03/2016

Aprovado em 28/10/2016

Publicado em 21/12/2016 